\title{
Publisher Correction: A systemic approach to mapping participation with low-carbon energy transitions
}

Jason Chilvers (D), Rob Bellamy (D), Helen Pallett and Tom Hargreaves (D)

Correction to: Nature Energy https://doi.org/10.1038/s41560-020-00762-w, published online 4 March 2021.

In the version of this Article originally published, the term 'low-carbon' was missing from the title. Furthemore, the wrong version of the Reporting Summary was used. All versions of the Article have been corrected and the Reporting Summary file replaced.

Published online: 12 March 2021

https://doi.org/10.1038/s41560-021-00812-x

(C) The Author(s), under exclusive licence to Springer Nature Limited 2021 